\title{
Sarcoidal granulomatous reaction due to tattoos: report of two cases*
}

\author{
Martha Cecilia Valbuena ${ }^{1,2}$ \\ Lorena Sánchez ${ }^{1,2}$
}

\author{
Victoria Eugenia Franco ${ }^{1,2}$ \\ Héctor David Jiménez ${ }^{1,2}$
}

DOI: http:/ / dx.doi.org/10.1590/abd1806-4841.20175860

\begin{abstract}
Numerous infectious, inflammatory and neoplastic complications secondary to tattoo placement have been reported in the literature. Within inflammatory complications sarcoidal granulomatous reactions have been described. We report two cases, a 55-year-old woman with yellowish infiltrated plaques on bilateral ciliary region, 16 years after the placement of a permanent tattoo in the eyebrows, and a 20-year-old tattoo artist who developed orange papules on 3 of his tattoos. Histopathology in both cases confirmed diagnosis of sarcoidal granulomatous reaction due to tattoo pigment.
\end{abstract}

Kewbords: Granuloma; Sarcoidosis; Tattoo

\section{INTRODUCTION}

Facial tattoos as a permanent or semi-permanent makeup are nowadays increasingly popular cosmetic procedures; nevertheless, reactions described in the literature secondary to this procedure are less frequent than those reported with decorative body tattoos. ${ }^{1}$ Among inflammatory complications secondary to tattoos, granulomatous reactions are usually associated to exogenous pigment that is injected into skin. These reactions can sometimes be the only sign of cutaneous or underlying systemic sarcoidosis, so in these patients it is appropriate to conduct additional studies and regular follow-up. ${ }^{2}$

\section{CASE REPORT}

A 55-year-old female patient reported a 2-year history of itchy persistent lesions on the eyebrows. She had a permanent makeup cosmetic tattoo 16 years before the onset of lesions (Figure 1). Histopathological examination of one of the lesions showed thick dermis with lymphocytic infiltrates around epithelioid granulomas involving the entire dermis, with presence of black pigment in the central portion (Figure 2). She was diagnosed with sarcoidal granulomatous reaction secondary to tattoo. Complementary studies included blood count, liver function tests, chest radiography and tuberculin skin test, all were within normal limits. Patient received two intralesional therapies with triamcinolone acetonide $(0.4 \mathrm{ml}$ in each eyebrow $-50 \mathrm{mg} / \mathrm{ml}$ ), showing improvement of lesions.

The second case was a 20-year-old man, tattoo artist, who reported the onset of painful lesions on 3 tattoos made one year and a half earlier (Figure 3). Histopathology revealed a sarcoidal granulomatous reaction (Figure 4). Systemic treatment with hydroxychloroquine $200 \mathrm{mg}$ /day was prescribed along with intralesional therapy with triamcinolone acetonide; however, patient was lost to follow-up.

\section{DISCUSSION}

Tattoos were traditional symbols among many cultures and continue to be a common practice. ${ }^{2}$ Its frequency has increased significantly among adolescents and young adults. ${ }^{3}$ Cosmetic facial tattoos were first introduced in the 80 s and during the last 10 years

\footnotetext{
Work submitted on 31.03.2016

Approved by the Advisory Board and accepted for publication on 27.11.2016

* Study conducted at the Hospital Universitario Centro Dermatológico Federico Lleras Acosta - Bogotá, Colombia.

Financial Support: None.

Conflict of Interests: None.

1 University Hospital Centro Dermatológico Federico Lleras Acosta - Bogotá, Colombia.

2 Fundación Universitaria Sanitas - Bogotá, Colombia.
} 
are used as a permanent or semi-permanent makeup in eyebrows, eyelids and lips. ${ }^{1}$

Tattoos can cause numerous cutaneous and systemic diseases. ${ }^{2}$ These include mainly local or systemic infections caused by bacteria such as methicillin-resistant Staphylococcus aureus, non-tuberculous mycobacteria and viruses such as human papilloma virus, hepatitis $B$ and $C$ virus, and $H I V .{ }^{8}$ Other potential complications are inflammatory reactions, generalized skin eruptions and non-melanoma skin cancer. ${ }^{3}$

Considering inflammatory complications secondary to tattoos, hypersensitivity reactions to pigments injected into the skin are relatively frequent. ${ }^{2}$ Ink may contain a variety of metals and organic substances, including mercury salts (red ink), cadmium sulfide (yellow ink), iron oxide (brown ink), carbon (black ink),

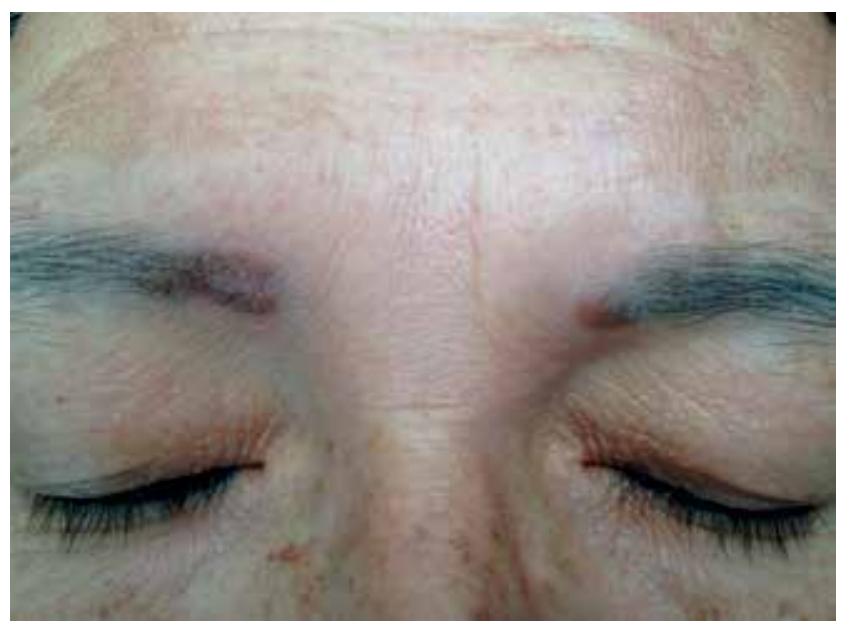

Figure 1: Previous treatments with hydrocortisone acetate cream 1\% and hydroquinone cream 3\% for one year, with no improvement. She denied respiratory or ocular symptoms. Physical examination revealed well-defined yellowish-brown infiltrated plaques located in the inner third of the eyebrows

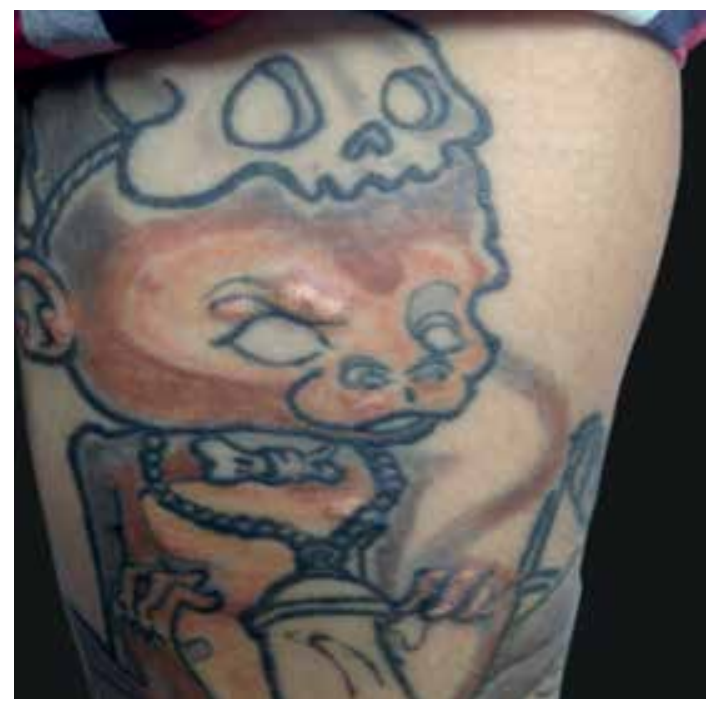

FIgURE 3: Physical examination showed areas of tattoos on his forearms, right thigh and foot with numerous salmon-colored papules and plaques with discrete scaling at the periphery
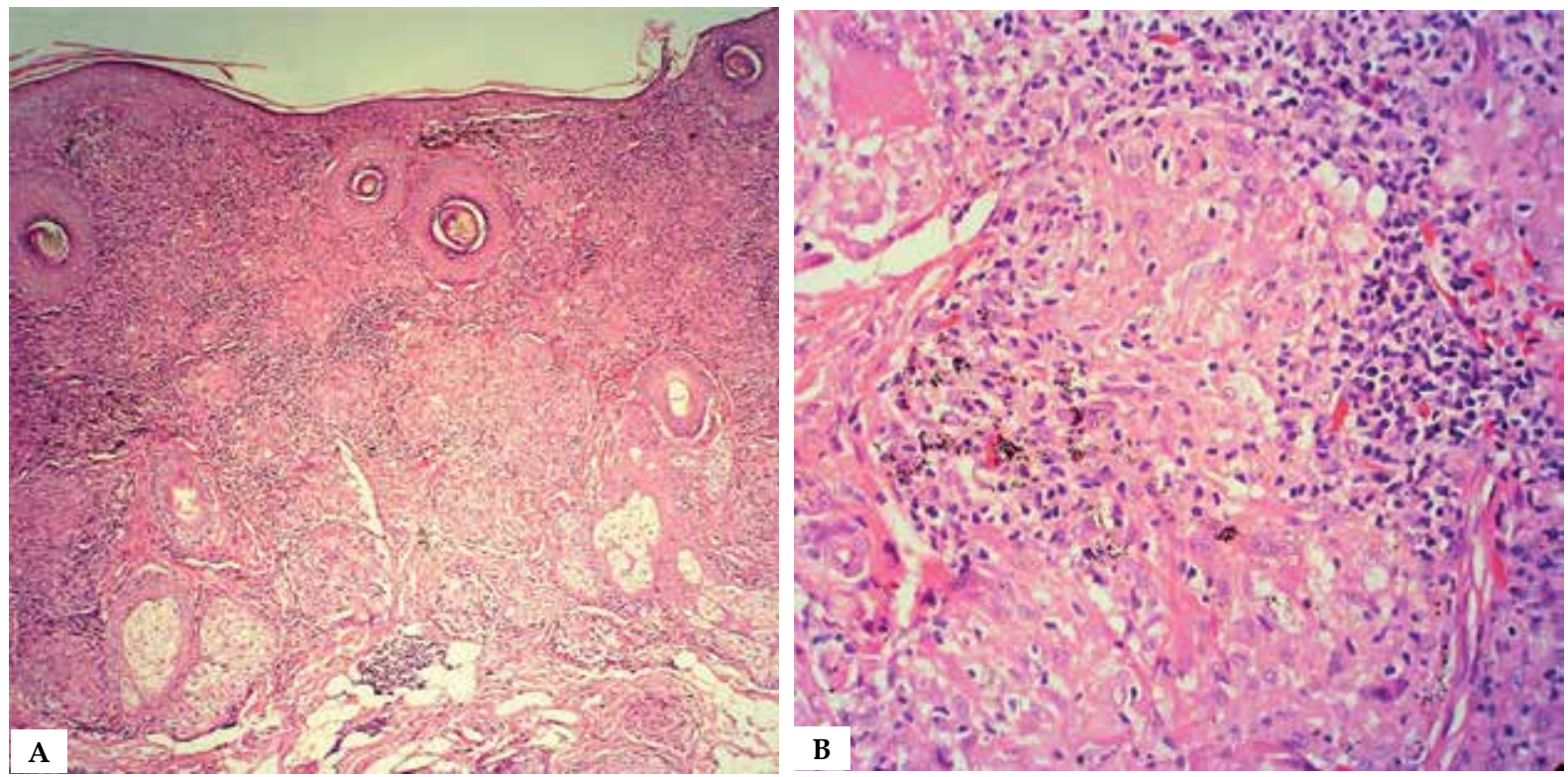

Figure 2: A. Dense granulomatous infiltrate involving the entire dermis with presence of pigmented granules in the papillary dermis. Hematoxylin \& eosin, X10. B. Epithelioid granulomas surrounded by lymphocytic infiltrates with black pigment in the central portion. Hematoxylin \& eosin, X40 

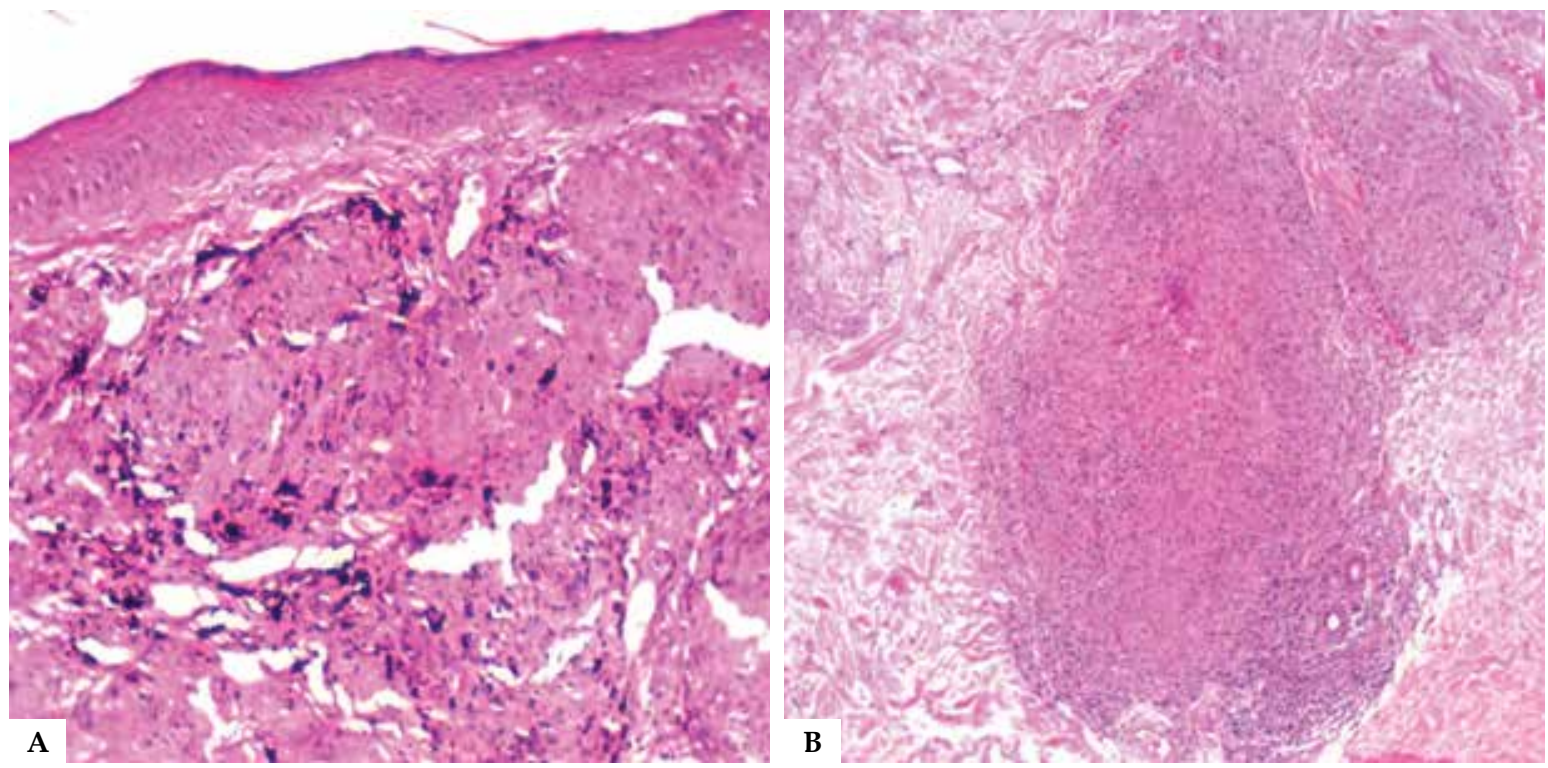

Figure 4: A. Epithelioid granulomas with central black pigment involving the entire dermis with mild inflammatory infiltrate. Hematoxylin \& eosin, X10. B. Epithelioid granuloma. Hematoxylin \& eosin, X10

cobalt chloride (blue ink) and manganese (purple ink), among others. $^{3}$ According to the histopathological findings these reactions are classified as: lichenoid, eczematous, pseudolymphomatous, photoallergic, morphea-like and granulomatous type.,4 Granulomatous reactions can be observed histologically as a foreign body reaction or sarcoidal type reaction. ${ }^{2}$

The first case of sarcoidal tattoo reaction was described in $1939{ }^{2}$ since then, there have been numerous reports, including those associated with cosmetic tattoos in women who underwent permanent makeup, as is the case of our first patient. ${ }^{5}$ Sarcoidal granulomatous reactions have a histopathologic pattern similar to sarcoidosis, with the presence of non-caseating epithelioid granulomas along with multinucleated giant cells, histopathology findings present in both of our cases. ${ }^{2,4}$

Pathogenic mechanisms leading to granulomatous immune response in an affected area of skin are still unknown. Depending on the etiology, the factor that triggers the formation of granulomas may have autoimmune or infectious origin. Lo Schiavo et al. ${ }^{6}$ proposed four possible scenarios for establishment of granulomas in the tattooed skin:

1. Hyperactive immune response: excessive activation of macrophages.

2. Decreased immune response: immune paradox.

3. Foreign body reaction: chronic immune response due to persistent antigen.

4. Perineural granulomatous inflammation.

One or more of these 4 theories could explain granulomas development in our patients.
Histopathologic evidence of sarcoidal granulomatous reaction in the presence of exogenous material (pigment) should not be considered as a criterion to exclude the diagnosis of cutaneous sarcoidosis. It is postulated that presence of exogenous material may act as antigenic stimulus that can induce persistent granulomatous inflammatory state leading to development of sarcoidosis in genetically susceptible individuals. ${ }^{6,7}$ Sanghavi et al. initially reported 14 of 19 cases of sarcoidal reaction to tattoo that were later diagnosed as systemic sarcoidosis, with latency periods ranging from one to 45 years. ${ }^{4}$ Despite the long period of latency between the permanent makeup tattoo and the onset of the sarcoidal reaction in our first case, there was no evidence of systemic sarcoidosis.

Sarcoidal reactions associated with tattoos are mainly treated with high- or ultra-high-potency topical or intralesional steroids that we offered for both patients. There are also reports of treatment of these reactions with allopurinol, a xanthine oxidase inhibitor, which reduces the production of free radicals involved in granulomas formation. ${ }^{8}$ Tetracyclines have also shown efficacy in the treatment of granulomatous diseases by decreasing the release of tumor necrosis factor alpha (TNF- $\alpha$ ), a cytokine involved in the formation of granulomas. ${ }^{9}$ Antimalarials are also useful because they inhibit antigen processing and presentation by antigen-presenting cells to CD4 T cells preventing the granuloma formation. ${ }^{10}$

Tattoos either for cosmetic or artistic purposes are an increasing practice worldwide, with a concomitant rise in tattoo-associated complications. For this reason, dermatologists and pathologists should be aware of these complications to approach an accurate diagnosis and therapy.] 


\section{REFERENCES}

1. Jones B, Oh C, Egan CA. Spontaneous resolution of a delayed granulomatous reaction to cosmetic tattoo. Int J Dermatol. 2008;47:59-60.

2. Morales-Callaghan AM Jr, Aguilar-Bernier M Jr, Martínez-García G, Miranda-Romero A. Sarcoid granuloma on black tattoo. J Am Acad Dermatol. 2006;55:S71-3.

3. Juhas E, English JC 3rd. Tattoo-Associated Complications. J Pediatr Adolesc Gynecol. 2013;26:125-9.

4. Sanghavi SA, Dongre AM, Khopkar US. Tattoo reactions--an epidemic on the surge: a report of 3 cases. Indian J Dermatol Venereol Leprol. 2013;79:231-4.

5. Morales C. Granuloma sarcoideo y granuloma a cuerpo extraño. Boletín CRIEl. Centro Dermatológico Federico Lleras Acosta E.S.E. 2005;3:9-13.

6. Lo Schiavo A, Ruocco E, Gambardella A, O'Leary RE, Gee S. Granulomatous dysimmune reactions (sarcoidosis, granuloma annulare, and others) on differently injured skin areas. Clin Dermatol. 2014;32:646-53.

7. Antonovich DD, Callen JP. Development of sarcoidosis in cosmetic tattoos. Arch Dermatol. 2005;141:869-72.

8. Martín JM, Revert A, Monteagudo C, Villalón G, Godoy R, Jordá E. Granulomatous reactions to permanent cosmetic tattoos successfully treated with topical steroids and allopurinol. J Cosmet Dermatol. 2007;6:229-31.

9. Monk E, Shalita A, Siegel DM. Clinical applications of non-antimicrobial tetracyclines in dermatology. Pharmacol Res. 2011;63:130-45.

10. Doherty CB, Rosen T. Evidence-Based Therapy for Cutaneous Sarcoidosis. Drugs. 2008;68:1361-83.

\author{
MAILING ADDRESS: \\ Martha Cecilia Valbuena \\ Avenida 1A \# 13A 61 \\ Bogotá, Colombia. \\ Email:marvalbuen@yahoo.com
}

How to cite this article: Valbuena MC, Franco VE, Sánchez L, Jiménez HD. Sarcoidal granulomatous reaction due to tattoos: report of two cases. An Bras Dermatol. 2017;92(5 Suppl 1): 138-41. 